\title{
VOZ, GÊNERO E SUBJETIVIDADE: CONSIDERAÇÕES FONOAUDIOLÓGICAS SOBRE INTERVENÇÕES COM TRANSGÊNEROS
}

\section{ARTIGO ORIGINAL}

PEREIRA, Daiane Regina ${ }^{1}$

PALLADINO, Ruth Ramalho Ruivo ${ }^{2}$

CUNHA, Maria Claudia ${ }^{3}$

PEREIRA, Daiane Regina. PALLADINO, Ruth Ramalho Ruivo. CUNHA, Maria Claudia. Voz, gênero e subjetividade: considerações fonoaudiológicas sobre intervenções com transgêneros. Revista Científica Multidisciplinar Núcleo do Conhecimento. Ano 05, Ed. 11, Vol. 18, pp. 149-165. Novembro de 2020. ISSN: 24480959, Link de acesso: https://www.nucleodoconhecimento.com.br/saude/voz-genero

\section{RESUMO}

O artigo propõe discorrer sobre a atuação da fonoaudiologia para a saúde da população transgênero, no âmbito do trabalho de redesignação vocal e a correlação com aspectos de identidade de gênero e subjetividade. Participaram da pesquisa seis fonoaudiólogos que atuam na promoção de saúde para população transgênero. Pesquisa qualitativa, realizada por meio da a aplicação de questionário composto por perguntas fechadas e abertas. Os dados coletados a partir do registro das respostas dos participantes foram analisados pela técnica de interpretação de dados análise de conteúdo, conforme proposta de Laurence Bardin (2011). Os resultados permitiram

\footnotetext{
${ }^{1}$ Bacharel em Fonoaudiologia; Mestranda em Fonoaudiologia.

2 Profa. Assistente - Doutor da Faculdade de Ciências Humanas e da Saúde da PUC/SP.

${ }^{3}$ Profa. Titular da Faculdade de Ciências Humanas e da Saúde da PUC/SP.
} 
identificar três categorias temáticas relevantes: Vulnerabilidade, Percepção da voz e Aspectos subjetivos. Conclui-se que a atuação da fonoaudiologia no trabalho de redesignação vocal com pessoas transgênero está atrelada às demandas sobre mobilidade de gênero, subjetividade e contexto social da população transgênero.

Palavras-chave: voz transgênero, redesignação vocal, transexualidade, fonoaudiologia, psicologia.

\section{INTRODUÇÃO}

O termo transexualidade é definido como "qualidade do que é transexual": o prefixo trans indica a ideia de através/além de/para além de e sexual faz referência às características anatômicas e fisiológicas distintivas entre os sexos feminino e masculino (DICIONÁRIO PRIBERAM, 2011). Portanto, o termo indica uma condição que ultrapassa e se destaca da estrutura orgânica. É uma condição, inclusive e sobretudo, de não reconhecimento desta estrutura enquanto corpo, instância fundamental de acolhimento do sujeito seguindo a perspectiva de Dias et al (2018, p. 166) que o "corpo é um território de fronteiras que articula a sua materialidade tanto por meio de traços físicos ou características observáveis como pelos traços demarcados pela linguagem que dá a ele uma capacidade de representação simbólica".

É importante salientar que a palavra transexual é um termo genérico que caracteriza homens e mulheres transexuais (JESUS, 2012):

Termo genérico que caracteriza a pessoa que não se identifica com o gênero que the foi atribuído quando de seu nascimento. Evite utilizar o termo isoladamente, pois soa ofensivo para pessoas transexuais, pelo fato de essa ser uma de suas características, entre outras, e não a única. Sempre se refira à pessoa como mulher transexual ou como homem transexual, de acordo com o gênero com o qual ela se identifica. (JESUS, 2012, p. 15)

Em relação a palavra transgênero, Jesus (2012) orienta que se trata de um termo "guarda-chuva" que acolhe a ampla diversidade de gênero: "conceito "guarda-chuva" que abrange o grupo diversificado de pessoas que não se identificam, em graus 
diferentes, com comportamentos e/ou papéis esperados do gênero que thes foi determinado quando de seu nascimento" (JESUS, 2012, p. 14). Neste sentido, este estudo adota o termo transgênero e/ou "trans" como referência às pessoas transexuais.

A literatura sobre transexualidade aponta inúmeros casos de rompimento de fronteiras entre o masculino e o feminino em diversas épocas e culturas. Nessa direção, Bento (2006) faz o seguinte questionamento acerca do alcance histórico da transexualidade: "seria correto afirmar que a experiência transexual esteve presente em outros momentos da história ocidental e em outras sociedades?".

A experiência de mobilidade e trânsito entre gêneros é antiga e imprecisa, como sugere a citação a seguir:

(...) encontramos referências sobre a transição entre os sexos a partir de Hipócrates e Heródoto (séc. V a. C), que narram a história dos citas (...) povo nômade que originalmente migrou da Ásia central para a Rússia meridional nos séculos VIII e VII a.C. A "doença dos citas", também mencionada pelo psiquiatra francês Jean-Étiene Esquirol, é igualmente conhecida como "doença feminina". Os soldados de Cita que marcharam contra o Egito e ousaram saquear o templo de Afrodite foram castigados pela deusa, que Ihes tirou a potência. (...). Atribuíam a si (os citas) a falta de virilidade, passavam a executar trabalhos femininos, vestiam-se e falavam como mulheres. Chamados de anarieus, esses homens eram venerados pelos habitantes daquela região, que os reverenciavam com temor. (JORGE; TRAVASSOS, 2018, p.49-50)

Outra referência de mobilidade entre os gêneros são as hijras, comunidade da Índia que apresenta como característica hábitos, traços, sentimentos e comportamentos associados ao feminino (JORGE; TRAVASSOS, 2018). Para a sociedade indiana são consideradas como um terceiro gênero e vivem em clã constituído com regras e costumes próprios. As hijras concedem bênçãos aos casamentos e aos recémnascidos. Durante os rituais, as hijras verificam o sexo do bebê e se esse for ambíguo - intersexual[4] - são consideradas hijras natas e terão status diferenciado na hierarquia do grupo (JORGE; TRAVASSOS, 2018). 
Observa-se, portanto, que o desejo de transicionar entre a face do feminino e do masculino é antigo e sua interpretação varia de acordo com a cultura na qual está inscrito. A transexualidade, compreendida pela perspectiva da nossa época e cultura, está relacionada à intervenção do saber médico/científico que estabelece diagnósticos e tratamentos para os transtornos de identidade: "a exigência de inscrever no corpo as insígnias femininas e masculinas através de cirurgias e hormonioterapia nasceu em um contexto muito específico, do avanço do discurso da ciência no mundo contemporâneo" (JORGE; TRAVASSOS, 2018, p. 53).

Nesse contexto, a Classificação Estatística Internacional de Doenças e Problemas Relacionados com a Saúde (CID) inclui a transexualidade no rol de doenças mentais. O CID-10, em vigor desde 1990, indica que ainda há perspectivas patologizantes em relação a transição de gênero (LIONÇO; CARVALHO; COACCI, 2018). No entanto, a Organização Mundial de Saúde (OMS) apresentou, em 18 de junho de 2018, a CID11, que entrará em atividade a partir de janeiro de 2022 (OPAS, 2018). A 11ª edição do CID apresenta uma outra classificação para a transexualidade: a categoria de "saúde mental" no capítulo relativo à "saúde sexual":

Importante destacar que na nova edição da CID, essas classificações diagnósticas psiquiátricas serão suprimidas. Uma nova classificação emerge, mas não mais como transtorno mental, a incongruência de gênero, uma resposta a luta internacional pela despatologização trans. (LIONÇO; CARVALHO; COACCI, 2018, p. 227)

Ressalta-se que alteração da CID atende uma importante demanda do movimento transgênero internacional e das organizações de travestis e transexuais no Brasil, a saber, a despatologização da transexualidade (MDH, 2018). Ou seja, retirá-la da categoria de patologia é uma das estratégias para desconstruir o estigma que lhe é atribuído (MDH, 2018). Nessa direção, essa mudança pode colaborar para a redução do preconceito sofrido por essa população, sem impedir a oferta de cuidados em saúde sobre o processo de transição de gênero de travestis e transexuais (MDH, 2018).

No contexto brasileiro, a proposta do Ministério da Saúde para o atendimento de pessoas transexuais no âmbito do Sistema Único de Saúde (SUS) está baseada nos 
princípios de universalidade, integralidade e equidade de atenção à saúde (ARÁN; MURTA, 2009).

O Processo Transexualizador no SUS foi instituído por meio da Portaria $\mathrm{n}^{0}$ 1.707/GM/MS, de 18 de agosto de 2008 e da Portaria no 457/SAS/MS, de 19 de agosto de 2008. Essas portarias estão pautadas na habilitação de serviços em hospitais universitários e na realização de procedimentos hospitalares (MS, 2018).

(...) De acordo com essa portaria, o Ministério da Saúde reconhece que a orientação sexual e a identidade de gênero são determinantes e condicionantes da situação de saúde, e que o mal-estar e o sentimento de inadaptação em relação ao sexo anatômico dos usuários transexuais devem ser acolhidos e tratados pelo SUS, seguindo os preceitos da universalidade, integralidade e da equidade da atenção. (ARÁN; MURTA, 2009, p. 18).

Em 30 de julho de 2013 foi publicada a Portaria no 859 que estabeleceu uma linha de cuidado organizada da atenção básica à especializada, sendo esta última focada não somente no procedimento cirúrgico e hospitalar, mas também na estruturação e ampliação dos serviços de atenção ambulatorial (MS, 2018). Em 19 novembro de 2013 foi publicada a Portaria no 2.803 que redefiniu e ampliou o Processo Transexualizador no Sistema Único de Saúde (MS, 2018).

Contudo, ressalta-se que a Portaria № 2.803/2013 do MS não inclui fonoaudiólogos na equipe multiprofissional, o que é questionável:

A feminilização ou masculinização da voz envolve o uso não habitual do mecanismo de produção da voz. São necessárias medidas preventivas para evitar a possibilidade de mau uso vocal e danos vocais a longo prazo. Todos os serviços de terapia de voz e comunicação devem incluir uma componente de saúde vocal. (ADLER et al., 2006 apud WPATH, 2017, p. 60)

Aspectos como comunicação e a voz se destacam na proposta da World Professional Association for Transgender Health[5] (WPATH), que inclui a comunicação - verbal e não verbal - como aspecto importante ao cuidado de saúde integral já que é um fator implicado na expressão de gênero (COLEMAN et al., 2012). Nesse documento, afirma-se que pessoas transexuais ou com variabilidade de gênero, que sintam a 
necessidade, podem desenvolver características vocais e/ou padrões de comunicação não verbal que promovam conforto à sua identidade de gênero (BARROS; CAVADINHA; MENDONÇA, 2017).

De acordo com Rameck (2001) a voz é, cultural e socialmente, um atributo importante no comportamento comunicativo e na percepção de gênero e, assim, a incompatibilidade entre estes aspectos não é desejável na medida em que:

A voz possui um papel extremamente importante na interação social, pois, além de servir como veículo (com seu potencial sonoro/ uso vocal) para comunicar os aspectos verbais, oferece informações sobre as características de identidade e de personalidade de um indivíduo, bem como de sua atitude e emoção (...) a voz tem implicações de construção social sobre a questão de gênero (masculinolfeminino). (RAMECK, 2001, p. 38)

$\mathrm{Na}$ busca de tal compatibilidade, existem intervenções cirúrgicas na laringe e hormonais para feminização da voz, porém a hormonioterapia feminina não tem efeito sobre a voz após a puberdade (COLEMAN et al, 2012). Por sua vez, o tratamento hormonal com testosterona, no caso de homens trans, promove diversos efeitos na fisiologia e na função vocal para uma voz grave (COLEMAN et al., 2012).

Sendo assim, as intervenções fonoaudiológicas quanto aos aspectos vocais e comunicação podem contribuir para uma transição de gênero efetiva, caracterizandose como seu principal objetivo a obtenção de padrões vocais e de comunicação tanto mais confortáveis como mais autênticos para a pessoa trans (BARROS; CAVADINHA; MENDONÇA, 2017). Nessa direção, sublinha-se que se a redesignação vocal não for assistida por um fonoaudiólogo especialista, podem ocorrer problemas significativos do ponto de vista tanto da fisiologia quanto da subjetividade desses sujeitos.

Feitas essas considerações, é importante explicitar que, inicialmente, as intervenções fonoaudiológicas quanto à redesignação vocal estavam embasadas na adaptação da frequência fundamental: elevar a frequência fundamental, no caso das mulheres trans, e abaixá-la nos homens trans (AZUL, 2016 apud BARROS; CAVADINHA; MENDONÇA, 2017). Em outras palavras: a altura vocal, ou altura tonal, refere-se à frequência de vibrações das pregas vocais, que gerará a frequência fundamental da 
emissão - um dos primeiros elementos da voz passível de caracterização de gênero (JACOBS, 2017).

Apesar da relevância contemporânea do tema, ainda são escassas as referências na literatura sobre o trabalho de comunicação e redesignação vocal para pessoas transgênero. Nesta perspectiva, o artigo tem por objetivo caracterizar a atuação de um grupo de fonoaudiólogos no âmbito do trabalho de redesignação vocal com pessoas transgênero na relação identidade de gênero e subjetividade.

\section{MÉTODO}

\section{CASUÍSTICA}

Participaram da pesquisa 06 fonoaudiólogos, atuantes no âmbito da Saúde Pública, especialmente em hospitais universitários dos estados de São Paulo e Rio de Janeiro, selecionados pelo método de amostragem Bola de Neve.

Critério de seleção: profissionais fonoaudiólogos atuantes na readequação vocal de transexuais. A tabela abaixo caracteriza os sujeitos:

Tabela 1 - Caracterização dos participantes da pesquisa

\begin{tabular}{|r|c|c|}
\hline $\begin{array}{r}\text { Ano de Formação } \\
\text { em Fonoaudiologia }\end{array}$ & $\begin{array}{c}\text { Tempo de Atuação com a População } \\
\text { Transgênero }\end{array}$ & \multirow{2}{*}{ Ambiente de Atuação Profis sional } \\
\hline 2005 & $50 \%-1$ à 5 anos & \multirow{2}{*}{$83,3 \%$ atuam em hospitais universitários } \\
\hline 2005 & $33,3 \%-10$ à 15 anos & \\
\hline 1997 & $16,7 \%-5$ à 10 anos & $16,7 \%$ atuam em hospitais públicos \\
\hline 1990 & 1975 &
\end{tabular}

Fonte: Autor

\section{COLETA DOS DADOS}

Os dados pertinentes à pesquisa foram coletados pela aplicação de um questionário composto por três perguntas fechadas e quatro perguntas abertas, elaboradas a partir 
do próprio objetivo do estudo. As perguntas fechadas se referiram aos seguintes aspectos: ano de conclusão da graduação em Fonoaudiologia, local e tempo de atuação com a população transexual. Para tais perguntas, o registro das respostas foi estabelecido por assinalação. As perguntas abertas se referiram aos seguintes aspectos: como motivação para atuar com a população transexual e aspectos de percepção da voz feminina e masculina, as quais os participantes puderam responder livremente.

O questionário foi disponibilizado digitalmente para os sujeitos em formato digital por meio da plataforma Google Forms (apêndice 1) e acessado pelos participantes após aceite do termo de consentimento livre e esclarecido - TCLE.

\section{CRITÉRIOS DE ANÁLISE DOS RESULTADOS}

Os dados coletados a partir da aplicação do questionário foram analisados pela técnica de interpretação de dados Análise de Conteúdo de acordo com a proposta de Bardin (2011), como se segue:

1. Pré-análise: inferências sobre os temas que se repetem com frequência a partir da leitura dos textos produzidos pelos participantes;

2. Exploração do material: elaboração das categorias temáticas com base na frequência de citação de características comuns entre os textos dos participantes;

3. Tratamento dos resultados: a interpretação dos resultados considerou a validação e significação do conteúdo implícito à fala do participante em relação a fundamentação teórica de embasamento da pesquisa;

\section{RESULTADOS}

Os resultados obtidos foram identificados em três categorias temáticas, descritas e ilustradas com fragmentos das respostas dos participantes a seguir. 


\section{CATEGORIA TEMÁTICA 1: VULNERABILIDADE}

Segundo os participantes, os fatores de dificuldade de acesso aos serviços de saúde, exposição a práticas discriminatórias, marginalização social, sujeição à ataques de violência física e/ou verbal são fatores que circundam a população trans e não devem ser desconsiderados do trabalho em saúde. Neste sentido, segundo os participantes, a contribuição do trabalho fonoaudiológico deve ir além das técnicas de intervenção para redesignação vocal, portanto, o profissional de saúde deve assumir uma abordagem amplificada para as demandas da população trans.

Sujeito 3: Para uma população ainda marginalizada, que carece de todo tipo de cuidado é muito importante um olhar mais amplo.

Sujeito 5: A necessidade é de auxílio a uma população em situação de vulnerabilidade importante, além de discriminada e vítima de violência constante.

Sujeito 2: (fala em relação à motivação para trabalhar com população transexual) (...) as condições de saúde dessa população, a dificuldade em ter acesso aos serviços de saúde.

\section{CATEGORIA 2: PERCEPÇÃO DA VOZ}

O ponto principal abordado nesta categoria é a intervenção dos componentes vocais relacionados com a percepção de identificação de gênero. A fala dos participantes em relação aos elementos da voz que contribuem para a identificação de gênero é diversificada. Alguns apontam a agudização ou gravidade (pitch) da voz como fator marcante para a percepção de gênero, já outros destacam componentes como ressonância vocal, prosódia e expressão corporal como pontos relevantes.

Sujeito 1: Para os pacientes (a percepção vocal) está associada ao" pitch" agudo ou grave, para mim à articulação e ressonância. 
Sujeito 2: Percebo que (a percepção vocal) a cada dia que se passa mais se distancia da frequência fundamental. (Para mim) Está mais no modo de comunicar, corpo, gestos etc.

Sujeito 5: Até o momento, fica evidente que características de gênero e voz são muito abrangentes e incluem dados de frequência, pitch, articulação, aspectos suprassegmentais da fala, além de prosódia (ritmo, velocidade de fala, curva melódica, prolongamento de vogais, dentre outros aspectos). Mas a identificação do gênero não se limita a essas características, inclui também gestos, expressão facial e corporal - mais específicas, mas também globais.

\section{CATEGORIA 3: ASPECTOS SUBJETIVOS}

Essa categoria se refere a preocupação dos profissionais em articular o trabalho de redesignação vocal com os conteúdos subjetivos manifestos pelos pacientes transexuais. Neste contexto, a voz pode representar para pessoas trans, dentre outros fatores, elemento importante para uma performance de gênero capaz de suprimir julgamentos ambíguos. Outros conteúdos retratam a redesignação vocal a partir da visão singular do/da pessoa do que para ele/ela representa o "ser feminina" ou "ser masculino".

Sujeito 1: Pacientes transgêneros em sua maioria estão em busca da adequação de voz ao gênero que se identificam, em busca de uma passabilidade e em sua maioria são mulheres trans (em relação a demanda para readequação vocal) - então, sim, alcançar uma voz feminina e masculina.

Sujeito 2: Algumas ainda procuram ter uma voz mais feminina ou masculina, mas a maioria busca por uma voz passável socialmente.

Sujeito 3: Trabalho com a noção que o paciente me traz do que pra ele é ser feminino ou masculino e atrelado a isto as questões orgânicas vão balizando os ajustes laríngeos possíveis. Sentir-se feminina para alguns pacientes é muito mais que ter 
gestos suaves e delicados e uma voz doce, com controle de intensidade, ajuste de vocabulário e entonação. Para alguns a busca é a não padronização.

\section{DISCUSSÃO}

A fala dos sujeitos participantes da pesquisa nos remete a uma questão discorrida na literatura: a vulnerabilidade a que a população LGBT está exposta. Nascimento; Sousa e Barros (2018), citam que transexuais e travestis estão expostos a vulnerabilidade social, o que pode determinar comportamentos de risco atrelados, principalmente, a marginalização e discriminação vivenciados por essa minoria.

Importante destacar que o uso do termo vulnerabilidade pela área da saúde começou no início dos anos 1980 , período de intensos estudos sobre a síndrome da imunodeficiência adquirida (aids), compartilhando conceitos da área dos Direitos Humanos (CARMO; GUIZARDI, 2018). O ser humano vulnerável, conforme partilhado pelas áreas da saúde e da assistência social, é aquele que está mais suscetível a danos, uma vez que possui desvantagens para mobilidade social o que caracteriza uma cidadania e qualidade de vida fragilizadas (CARMO; GUIZARDI, 2018).

Não é possível refletir sobre equidade social sem considerar o contexto de vida dos sujeitos. Carmo e Guizardi (2018) destacam:

Quando refletimos sobre justiça social não é possível desconsiderar o contexto de vida dos sujeitos e como tais contextos podem contornar suas formas de expressividade, exercendo influências sobre as maneiras como se posicionam na sociedade e como se enxergam. A omissão e/ou o recuo do poder público em seu papel de proteção social cria ciclos de reprodução de situações de opressão, não só no sentido da desigualdade no acesso a políticas e serviços, mas de cerceamento da livre expressão e lutas dos sujeitos, o que esconde a dimensão coletiva da vivência das populações em contextos de produção de vulnerabilidades. (CARMO, GUIZARDI, 2018, p. 6)

Nascimento et al. (2018) e Garcia et al. (2016) citam que a população de travestis e transexuais está exposta as vulnerabilidades em saúde e comportamentos de risco. A acessibilidade à saúde é atravessada por uma série de iniquidades, violação e obstáculos dinamizados pelo processo de estigma, discriminação e preconceito por 
essa população. Em resposta a isso, são encontradas nessa população complexos indicadores de saúde: concentração de HIV\Aids entre transexuais e homens que mantém relações sexuais com homens, altos índices de distúrbios mentais e ações suicidas entre jovens e adultos LGBT e maior propensão ao uso de álcool e drogas psicoativas (GARCIA et al., 2016).

No que se refere a categoria percepção de voz, Schneider e Courey (2016) apontam que o pitch é um componente valorizado para a identificação do gênero feminino considerando que o aumento do pitch influencia o grau de feminização da voz. Todavia, adequar o pitch no parâmetro compreendido para voz feminina/aguda (pitch médio feminino não transgênero é de $225 \mathrm{~Hz}$ ) não garante, necessariamente, o julgamento de ouvintes leigos favorável para voz feminina (SCHNEIDER; COUREY, 2016). De acordo com os autores, outros fatores de composição da voz, como amplitude de tom, entonação, ressonância e a qualidade da voz desempenham papéis variados para a identificação de gênero, como também apontaram alguns participantes.

Ainda nessa direção, a literatura aponta que a autopercepção de pessoas transgênero em relação à sua qualidade de voz é um aspecto fundamental para uma transição bem-sucedida. A relação autopercepção de voz e qualidade de vida é recorrente na literatura e na opinião de especialistas, porém há carência de estudos dessa natureza quando se explora a autopercepção de voz de pessoas trans. Segundo Hancock et al. (2011), os estudos sobre autopercepção de voz e satisfação tem sua potencialidade nas questões relacionadas aos distúrbios de voz e não necessariamente na influência da voz relacionada à identidade de gênero.

Barros et al. (2017) citam que estudos sobre a voz de homens trans são escassos, o que pode estra relacionado ao fato científico de que os homens trans não teriam problemas vocais ou necessidade de atenção relacionada a voz devido a administração do hormônio testosterona que levaria a uma transformação satisfatória de suas estruturas de produção vocal e, consequentemente, da sua voz. Porém, a hormonioterapia não garante, necessariamente, satisfação quanto a nova voz (BARROS; CAVADINHA; MENDONÇA, 2017). 
A transição de gênero de masculino para feminino exige ajustes mais complexos para a adequação da voz à nova identidade social - a voz masculina possui padrões de ressonância, velocidade de fala, intensidade, pitch e outras características suprassegmentais que a diferem da voz feminina (SCHMIDT, 2018). O sujeito 1 pontua que há uma tendência pela busca de uma voz idealmente feminina ou masculina, sendo esta uma demanda expressiva das mulheres trans. Schmidt (2018), reafirma tal fala: "a adequação da voz é uma das principais questões que as mulheres transgênero enfrentam durante a transição, e a satisfação ou insatisfação com esta vem a ser um importante parâmetro de como as políticas de transição de gênero estão funcionando no país".

A implicação dada pelo sujeito 5 de que a identificação de gênero não se limita aos atributos da voz e/ou da fala, sugere que a composição do cuidado para a pessoa trans pretende incorporar não apenas metas objetivas, ajustes de frequência, por exemplo, mas também aspectos subjetivos.

Diante das questões subjetivas, destaca-se o desejo de passabilidade - termo usado na comunidade transgênero e que implica em determinado indivíduo trans "passar", ser identificado pelo gênero por ele assumido (PONTES; SILVA, 2018). Os sujeitos 1 e 2 também ressaltam a preocupação da pessoa trans sobre atingir uma voz "passável socialmente", portanto, uma voz capaz de suprimir ambiguidades ou incoerências no reconhecimento do gênero feminino ou masculino.

A relevância da voz para homens e mulheres trans convoca a importância da terapia fonoaudiológica ancorada numa abordagem crítica e atenta às questões sociais e subjetivas intrínsecas a expressão de gênero, além dos aspectos singulares da comunicação e da voz.

\section{CONCLUSÃO}

A implicação da Fonoaudiologia no processo de transição de gênero representa potencial relevante para a promoção da saúde de pessoas transgênero. Os sujeitos participantes da pesquisa compartilharam conceitos e pontos de vistas sobre a 
redesignação vocal que, apesar de não homogêneos, apontam para modos de intervenção fonoaudiológica que privilegiem não somente a diversidade de gênero como a singularidade de cada sujeito.

Nesse contexto, cabe pontuação final sobre a não referência explícita à Fonoaudiologia nas portarias de viabilidade do Processo Transexualizador no Sistema Único de Saúde (SUS). Sugere-se, assim, a intensificação de pesquisas fonoaudiológicas que ressaltem e questionem tal lacuna.

\section{REFERÊNCIAS}

ÁRAN, Márcia; MURTA, Daniela. Do diagnóstico de transtorno de identidade de gênero às redescrições da experiência da transexualidade: uma reflexão sobre gênero, tecnologia e saúde. Physis, Rio de Janeiro, v. 19, n. 1, p. 15-41, 2009.

BARROS, Alana Dantas. A relação entre a voz e expressão de gênero: a percepção de pessoas transexuais. Brasília, 2017. 92 f. Dissertação (Mestrado em Saúde Coletiva) - Faculdade de Ciências da Saúde, Universidade de Brasília, Brasília, 2017.

BARROS, Alana Dantas; CAVADINHA, Edu Turte; MENDONÇA, Ana Valéria Machado. A percepção de homens trans sobre a relação entre voz e expressão de gênero em suas interações. Tempus (Brasília), Brasília, v. 11, n. 4, p. 9-24, 2017.

BENTO, Berenice. Corpo e História. In: A reinvenção do corpo: sexualidade e gênero na experiência transexual. Rio de Janeiro: Garamond, 2006.

CARMO, Michelly Eustáquia do; GUIZARDI, Francini Lube. O conceito de vulnerabilidade e seus sentidos para as políticas públicas de saúde e assistência social. Cad. Saúde Pública, Rio de Janeiro, v. 34, n. 3, p. 1-14, 2018.

COLEMAN, Eli et al. World Professional Association for Transgender Health (WPATH). 
<https://www.wpath.org/media/cms/Documents/SOC\%20v7/SOC\%20V7_Portuguese .pdf. Acesso em 10 jul. 2019.

DIAS, Alfrancio Ferreira; ZOBOLI, Fabio; SANTOS, Adriana Lohanna dos. O banheiro como espaço político de gênero. Reflexão e Ação, Santa Cruz do Sul, v. 26, n. 2, p. 165-181, 2018. ISSN 1982-9949.

GARCIA, Cíntia de Lima; ALBUQUERQUE, Grayce Alencar; DREZETT, Jefferson; ADAMI. Saúde de Minorias Sexuais do Nordeste Brasileiro: Representações, Comportamentos e Obstáculos. J. Hum. Growth Dev., São Paulo, v. 26, n. 1, p. 95100, 2016.

GASKELL, George; BAUER, Martin W. Entrevistas individuais e grupais. In: . Pesquisa qualitativa com texto, imagem e som: um manual prático. Rio de Janeiro: Editora Vozes, 2013. 64-89.

GODOY, Arilda Schmidt. Pesquisa qualitativa: tipos fundamentais. Revista de Administração de Empresas, São Paulo, v. 35, n. 3, p. 20-29, 1995.

HANCOCH, Adrienne B.; KRISSINGER, Julianne; OWEN, Kelly. Voice Perceptions and Quality of Life of Transgender People. Journal of Voice, v. 25, n. 5, p. 553-558, 2011.

JACOBS, Daiane Dordete Steckert. Corpo vocal, gênero e performance. Rev. Bras. Estud. Presença, Porto Alegre, v. 7, n. 2, p. 359-381, 2017.

JESUS, Jaqueline Gomes de. Orientações sobre a população transgênero: conceitos e termos. Brasília: Autor, 2012. Disponível em: $<\mathrm{https}$ ://issuu.com/jaquelinejesus/docs/orienta_es_popula_o_trans>. Acesso em: 02 ag. 2020.

JORGE, Marco Antonio Coutinho; TRAVASSOS, Natália Pereira. Sexo e gênero. In: Transexualidade: 0 corpo entre o sujeito e a ciência. Rio de Janeiro: Zahar, 2018. 27-48. 
LIONÇO, Tatiana; CARVALHO, Mário Felipe; COACCI, Thiago. 40 anos da história do movimento LGBT no Brasil: memórias, desafios atuais e novas perspectivas entrevista com Marco José de Oliveira Duarte. Rebeh (Ceará), Ceará, v. 01, n. 04, p. 217-230, 2018.

MINISTÉRIO DA MULHER, DA FAMÍLIA E DOS DIREITOS HUMANOS. Disponível em: $\quad$ <https://www.gov.br/mdh/pt-br/assuntos/noticias/2018/junho/organizacaomundial-da-saude-retira-a-transexualidade-da-lista-de-doencas-e-disturbiosmentais>. Acesso em 4 mar. 2019.

MINISTÉRIO DA SAÚDE. ATENÇÃO ESPECIALIZADA E HOSPITALAR. Disponível em: $<$ http://portalms.saude.gov.br/atencao-especializada-ehospitalar/especialidades/processo-transexualizador-no-sus/acesso-e-regulacao>. Acesso em: 4 mar. 2019.

NASCIMENTO, Hosana Maria; SOUSA, Junior Araújo; BARROS, Claudia Renata dos Santos. Atendimento em saúde para as travestis e transexuais: revisão sistemática da literatura (2008-2017). Rebeh (Ceará), Ceará, v. 01, n. 04, p. 40-58, 2018.

NETO, Henrique Luiz Caproni. Transgêneros e o mundo do trabalho. In: VAZ, Fábio Oliveira. Gestão e estratégia no mundo do trabalho. Maringá (PR): Uniedusul, 2019. Disponível em: <https://uniedusul.com.br/wpcontent/uploads/2019/12/LIVRO-2-GEST\%C3\%83O-E-ESTRAT\%C3\%89GIA-NOMUNDO-DO-TRABALHO-01.pdf>. Acesso em: 04 abr. 2019.

OPAS BRASIL. OMS divulga nova Classificação Internacional de Doenças. Disponível em:

$<$ https://www.paho.org/bra/index.php?option=com_content\&view=article\&id=5702:om s-divulga-nova-classificacao-internacional-de-doencas-cid-11\&ltemid=875>. Acesso em: 12 nov. 2019.

PONTES, Julia Clara de; SILVA, Cristiane Gonçalves da. Cisnormatividade e passabilidade: deslocamentos e diferenças nas narrativas de pessoas trans. PERIÓDICUS (Salvador), Salvador, v. 1, n. 8, p. 396-417, 2018. 
RAMECK, Maruska Freire. Dinâmicas da voz e do gênero: uma questão de poder. São Paulo, 2001. 230 f. Tese (Doutorado em Fonoaudiologia) - Pontifícia Universidade Católica de São Paulo, São Paulo, 2001.

SCHMIDT, Jeanne Gabriele et al. O desafio da voz na mulher transgênero: autopercepção de desvantagem vocal em mulheres trans em comparação à percepção de gênero por ouvintes leigos. Rev. CEFAC, São Paulo, v. 20, n. 1, p. 7986, 2018.

SCHNEIDER, Sarah; COUREY, Mark. Transgender voice and communication - vocal health and considerations. Disponível em: $<$ https://transcare.ucsf.edu/guidelines/vocal-health>. Acesso em 10 jul. 2019.

TRANSEXUALIDADE. In: DICIONÁRIO PRIBERAM DA LÍNGUA PORTUGUESA. Priberam Informática, $2011 . \quad$ Disponível em <https://dicionario.priberam.org/transexual>. Acesso em: 4 mar. 2019. 


\section{APÊNDICE}

1. Ano de formação em fonoaudiologia:

2. Há quanto tempo trabalha com aperfeiçoamento vocal de pessoas transgênero?

a) 1 a 5 anos

b) 5 a 10 anos

c) 10 a 15 anos

d) Mais de 15 anos

3. Em qual instituição trabalha?

a) Hospital Universitário

b) Centro de Referência LGBT

c) Centro de Referência DSTVAIDS

d) Centro Regional de Especialidades - (CRE)

e) Clínica particular

f) Outros:

4. O que te motivou a atuar com a saúde da população transgênero?

5. Na sua visão, qual a contribuição da fonoaudiologia para a saúde das pessoas transgênero?

6. Na sua perspectiva de atuação, a percepção de uma voz dita feminina ou masculina está associada a quais aspectos?

7. Partindo de sua resposta na pergunta anterior, a demanda dos usuários ao tratamento vocal se dá no campo da readequação (alcançar uma voz feminina ou masculina) ou no campo do aperfeiçoamento vocal? 


\section{APÊNDICE - REFERÊNCIAS DE NOTA DE RODAPÉ}

4. Intersexual é uma nomenclatura nova que se refere aos hermafroditas, portanto, indivíduos que apresentam órgãos reprodutores ambíguos. (JORGE; TRAVASSOS, 2018; p.52).

5. Organização educacional e profissional interdisciplinar sem fins lucrativos dedicada à saúde transgênero. Autoria do guia WPATH seguirá como Coleman et al (2012).

Enviado: Junho, 2020.

Aprovado: Novembro, 2020. 